\title{
LABOUR PRODUCTIVITY IMPROVEMENT BY WORK STUDY TOOLS OF FIBER COMPOSITE COMPANY
}

\author{
Amol Nayakappa Patil ${ }^{1}$, M Prabhakaran ${ }^{2}$ \\ ${ }^{1}$ Assistant Professor, Department of Mechanical Engineering, Agnel Institute of Technology and Design, Goa, India \\ ${ }^{2}$ Assistant Professor, Department of Mechanical Engineering, Agnel Institute of Technology and Design, Goa, India.
}

\begin{abstract}
Market trends and consumer requirements get modernize in relatively fast comportment. Globalization developed trade opportunities to fulfill consumer needs, but along also resulted in competition, improved quality and increased productivity. The quality and quantity is being realized by changing conventional manufacturing to automated manufacturing with minimum labour supervision, which is more feasible for large industries and MNCs. But. SMEs backbone of country economy cannot afford for radical process changes as it requires huge investment. The paper aims to demonstrate application of work study tools in small fiber composite company. The research has been carried out at fiber composite company manufacturing swimming pool filter. The simple work study tools are used to study process layout, cycle time and distance travelled during manufacturing. The idle time is been identified along with the distance travelled; accordingly process layout modification is suggested based on the economic analysis which gives indicative measure of profit leading to increase in productive rate.
\end{abstract}

Keywords: SMEs, Labour Productivity, Work Study, Process Chart, Multi Activity Chart, Travel Chart, Fiber Composites, Cycle Time

\section{INTRODUCTION}

Manufacturing world is dynamic in nature which is everchanging. Market trends demand continuous improvement in product and process. Total Quality Management, Total Preventive Maintenance, Business Process Reengineering, Organizational development, Kaizen, 5S are different methods available for manufacturing with aim to improve operation [1]. But, before any improvement could be done it is required to define present process status with well defined available measures. Productivity is one of such measure which defines quantitative relationship between production and resources used for production. It is expressed as ratio of output to input. It is efficiency of production system and leading indicator applied in an enterprise or in economy sector [2]. Productivity could be improved by using any of the above mention methods, but implementation of such methods requires excessive training, top management support, continuous auditing, and also investments to carry out changes in production setup. Sometime methods mention are economically infeasible for SMEs which is added up with scarcity of skilled labour constrained minimum wage.

Work study is one of oldest technique to improve productivity and based on detail process study. Work study is divided into method study and work measurement. Method study aims in reducing unnecessary operations while work measurement deals with investigating and eliminating production loss time [3]. Work study eliminates wasteful use of resources, cuts unnecessary and extra work, minimizes production time, simplifies method, thus improving productivity without additional expenditure [4]. So, researches are more focusing on such simple techniques. Simple work study tools like activity chart, process flow chart, were used to find out bottleneck operation that consume more time in comparison with points at motor vehicle inspection station and some solution were identified to improve station [5]. Production capability was improved for small scale industry producing Stay vane of Francis turbine. Work study tools like systematic observation, flow chart and stopwatch time study, were used to improve work process in company with aim of reducing production time and number of process by identify problems in the production work process [6].

This paper focuses on application of process flow chart, multi activity chart and travel chart simple work study tools at swimming pool filter manufacturing small enterprise. Cycle time is determined based on data as benchmark time and process improvement activities initiated based on research outcome.

\section{CASE STUDY}

This study is carried out in Fiber Composites Company, a small scale industry manufacturing fiber composite housing of swimming pool filter in Goa, India. The swimming pool filters manufactured by company are either side or top mounted using fiberglass and polyester resin with winding process. Most of work in fiber composite company is done manually by their operators. Sometimes, the production takes extra time to produce pool filter as no standard time is defined for production. Moreover, the production department does not have any fixed or standard cycle time 
for process. Even company does not have proper layout and there is loss of time in the men movement. The production setup and practices used currently in the company are time consuming as regard of men movement. Research focuses in reducing time required for production, making effective labour utilization and make the process simple to serve objective research uses work study tools.

Research focuses on study of existing plant layout and determine the work cycle time required to produce swimming pool filter model TM860-32 and use of simple work study tools to reduce men movement and cycle time thus leading to effective utilization of labour to increase labour productivity.

\subsection{Plant Layout}

Figure 1 shows top view of present plant layout, which is indicative of different production stations along with the men travel distance while product move from one station to next towards the completion of product.

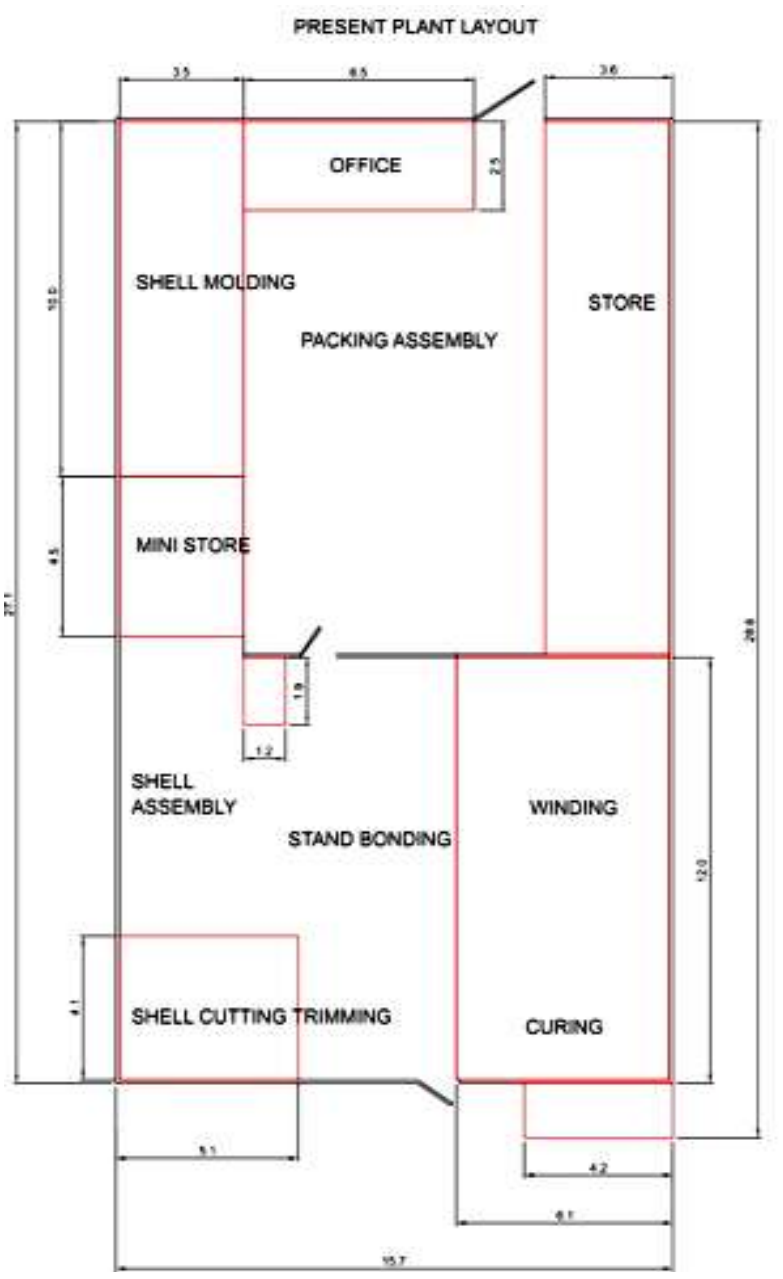

Fig -1: Present Plant Layout

\subsection{Process Detail}

Swimming pool filter model TM860-32 manufacturing has three main processes i.e. inspection of fitments according to Quality plan, shell moulding and stand moulding according to work and manufacturing instruction as mention quality manual. The raw material used for shell and stand is polyester resin and glass fiber. Once the shell and stand is moulded they are assembled together to make final product. In process quality checks assure product meets quality standard and dimensional requirement. Once product is ready hydro test is carried out to make sure product can withstand required pressure requirements without any leakages. Detail process is grasped in Figure 2 indicating all processes involved along with time required for each process, their altogether twenty processes and four inspection points. Study of process and cycle time concluded fiber composite company produces five TM86032 model swimming pool filters per day.

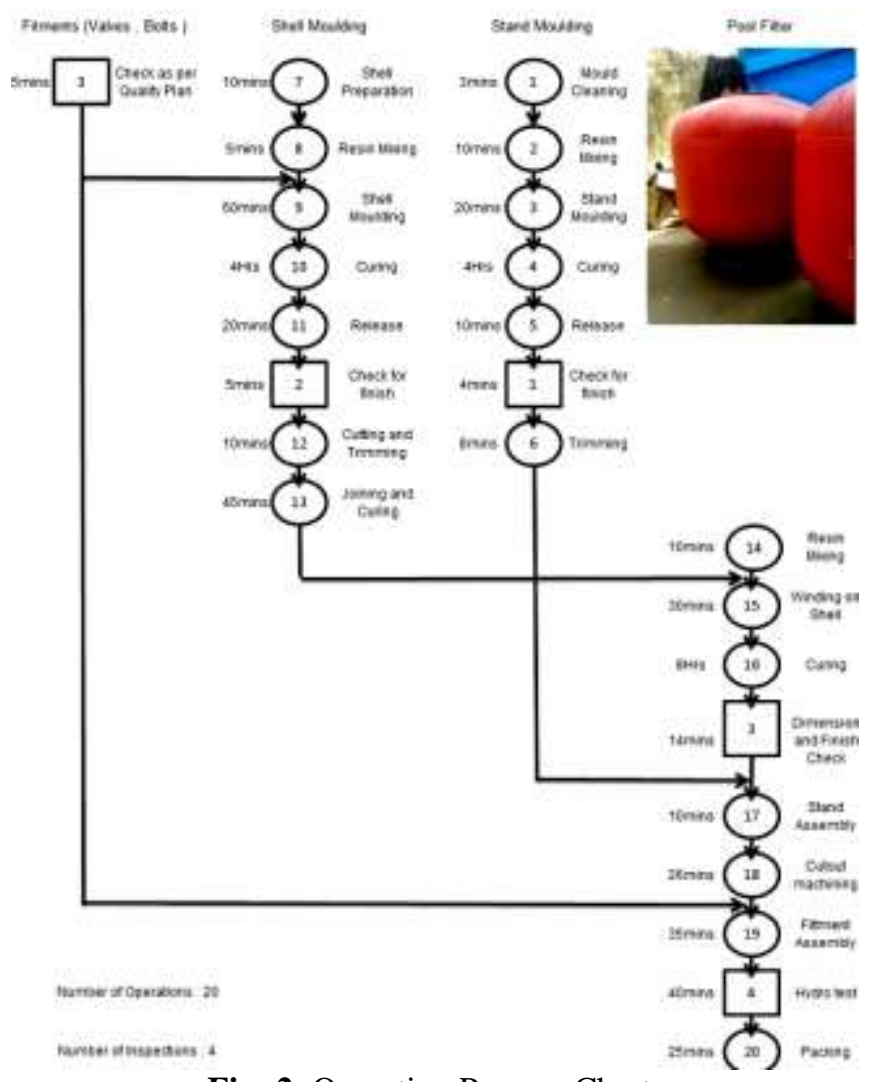

Fig -2: Operation Process Chart

\subsection{Process Amplification}

Shell moulding and stand moulding are the two major processes in manufacturing of swimming pool filter. These processes are carried out manually and have major contribution towards cycle time reduction. The processes are carried out in much unplanned manner. The detail flow study for same is done in amplified way and the operations involved, time required, distance travelled, delays observed are monitored and recorded using flow process chart, while suggestion also recommended reducing cycle time and traveling distance.

Shell mouding process requires initial shell moulding using layup method and later winding using machine on shell mould. Shell moulding has six operations, one inspection, 
nine transportation, and two delays. Shell winding has eight operations, two inspections, six transportation and one delay. Proper housekeeping, better communication to store, training labour to carry out inspection and use of hand trolleys will eliminate transportation, inspection and delay thus reducing cycle time $42 \mathrm{mins}$ and travel distance by 36.4 meters. The detailed flow of shell moulding is shown in Chart 1. and shell winding in Chart 2.

\begin{tabular}{|c|c|c|c|c|c|}
\hline \multirow{2}{*}{ Eloment Description } & \multicolumn{2}{|c|}{ Symbd } & \multirow{2}{*}{ Distance } & \multirow{2}{*}{$\begin{array}{l}\operatorname{Tims} \\
\langle\mathrm{Sec})\end{array}$} & \multirow{2}{*}{$\begin{array}{l}\text { Modíncation } \\
\text { Recommended }\end{array}$} \\
\hline & $O \Rightarrow D$ & $\square \nabla \ll$ & & & \\
\hline To Shel Area & & & 4.2 & $3 t$ & \\
\hline Shent Solection & & & & 720 & Proper arrangment \\
\hline Shel Noulding area & & & 42 & 50 & \\
\hline Shes prepartion & & & & 600 & \\
\hline to Stores: & & & 25 & 250 & \\
\hline Resmfiner Reguistion & & & & 720 & Work Onser to stores \\
\hline Sheal Mouldng area & & & 25 & 275 & \\
\hline Shel Moulding & & & & 3600 & \\
\hline to cuning & & & 2 & 90 & \\
\hline Curing & & & & 14000 & \\
\hline Relesses & & & & 1200 & \\
\hline Chock for finish & & & & 300 & $\begin{array}{l}\text { Releasse and check } \\
\text { nesesration }\end{array}$ \\
\hline Shel to culting area & & & 19 & 210 & \\
\hline To Shel Area & & & 18 & 160 & $\begin{array}{l}\text { Mowemert using } \\
\text { Hand troliey }\end{array}$ \\
\hline Shel to cutting area & & & 18 & 210 & \\
\hline Cutting and Tremeing & & & & 600 & \\
\hline Soining arou & & & 5 & 120 & \\
\hline bainng and Cuting & & & & 3650 & \\
\hline Stores anea & - & & 16 & 210 & \\
\hline
\end{tabular}

Chart -1: Process Flow Chart-Shell Moulding

\begin{tabular}{|c|c|c|c|c|c|c|c|c|}
\hline \multirow{2}{*}{ Element Description } & \multicolumn{5}{|c|}{ Symbol } & \multirow{2}{*}{$\begin{array}{c}\text { Dastance } \\
(\mathrm{m})\end{array}$} & \multirow{2}{*}{$\operatorname{Time}_{(\mathrm{Sec})}$} & \multirow{2}{*}{$\begin{array}{l}\text { Nodfication } \\
\text { Raccomemendice }\end{array}$} \\
\hline & O & $\Rightarrow D$ & $\square$ & $\nabla$ & a & & & \\
\hline To stores: & & & & & & 25 & 250 & \\
\hline Rosinf bor Requistion & & & & & & & 720 & Work Order \\
\hline To winting & & & & & & 26 & 200 & \\
\hline Wndng & & & & & & & 300 & \\
\hline securing & & & & & & 3 & 40 & \\
\hline Curing & & & & & & & 286000 & \\
\hline Omension check & & & & & & & 420 & \\
\hline to stand asarnbey & & & & & & 5 & 240 & \\
\hline Stand assembiy & & & & & & & 870 & \\
\hline Quring & & & & & & & 1200 & \\
\hline Out out machining & & & & & & & 1200 & \\
\hline Frment assemaly & & & & & & & 600 & \\
\hline tea toptro tess & & & & & & 14 & 230 & \\
\hline Hodro test & & & & & & & 900 & \\
\hline to packing & & & & & & 22 & 300 & \\
\hline Cleosing & & & & & & & 400 & \\
\hline Packng & $\mid$ & & & & & & 500 & \\
\hline
\end{tabular}

Chart -2: Process Flow Chart-Shell Winding
Since company maintains stock of stands required for different models, study of stand moulding is considered as vital, instead shell assembly stand is given importance. As shell winding is completed, shell is allowed to cure. After curing shell is taken to stand assembly section. Adhesion is applied on stand, allowed to cure and later shell is assembled with stand. In present method one operator with aid of lifting equipments carries out shell stand assembly and requires $14.5 \mathrm{mins}$ per job and idle time is $10 \mathrm{mins}$, with indicative efficiency of $31 \%$. With proper spacing and time utilization one operator can carry out multi assembly, thus proper utilization of time. Chart 3, multi activity chart shows effective time utilization, where operator can carry three shell bonding on stand resulting in reducing cycle time to $6.68 \mathrm{mins}$ and idle time $6.5 \mathrm{mins}$ with efficiency of $68 \%$.

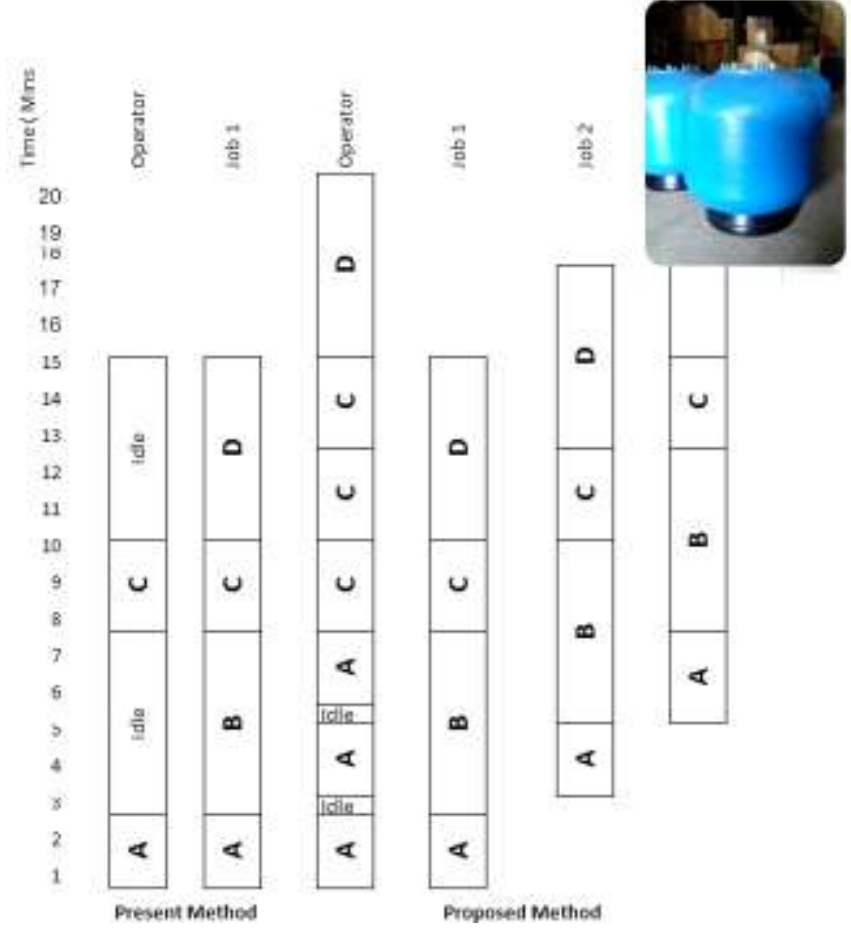

Chart -3: Multi Activity Chart

Process A-Adhesion application, B-Adhesion drying, CAssembly pool filter, D-Allow to cure

Fiber composite layout study is carried out using travel chart, Chart 4 shows men distance travelled during completion of swimming pool filter model TM860-32. The total distance travelled during men movement from one station to next is $181 \mathrm{~m}$. 


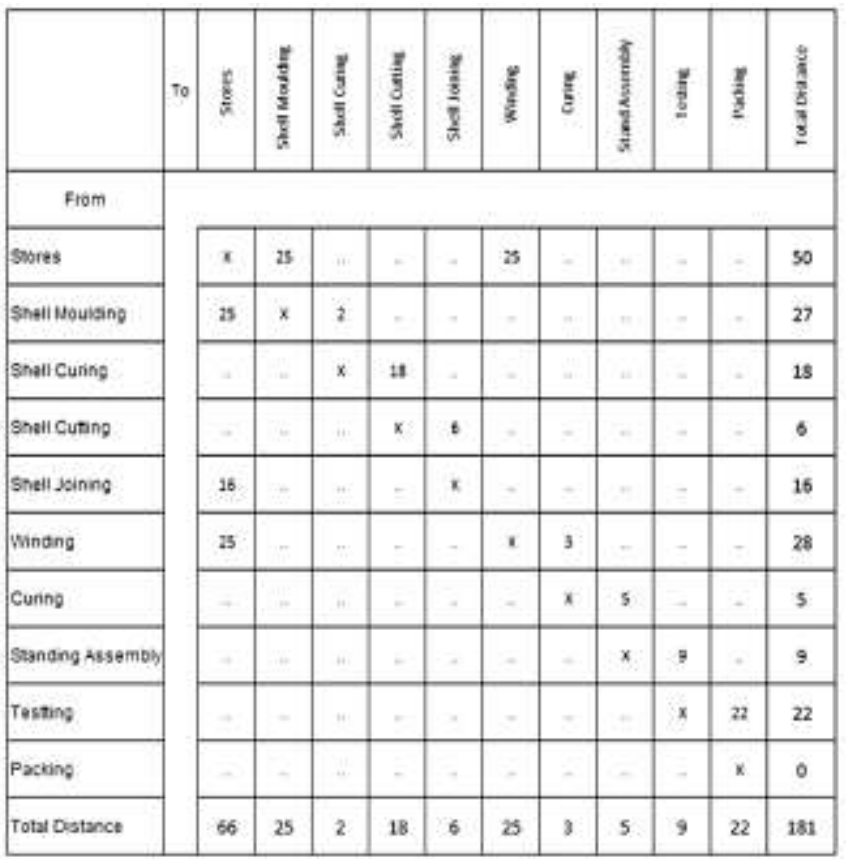

Chart -4: Travel Chart-Present Layout

Taking all process flow constraint, resource availability various modified layout study is carried out. The layout that gives minimum travel distance is sown in Figure 3 and corresponding travel distance is shown in chart 5. The total travel distance for modified layout is $132 \mathrm{~m}$ which saves $49 \mathrm{~m}$ travel distance.

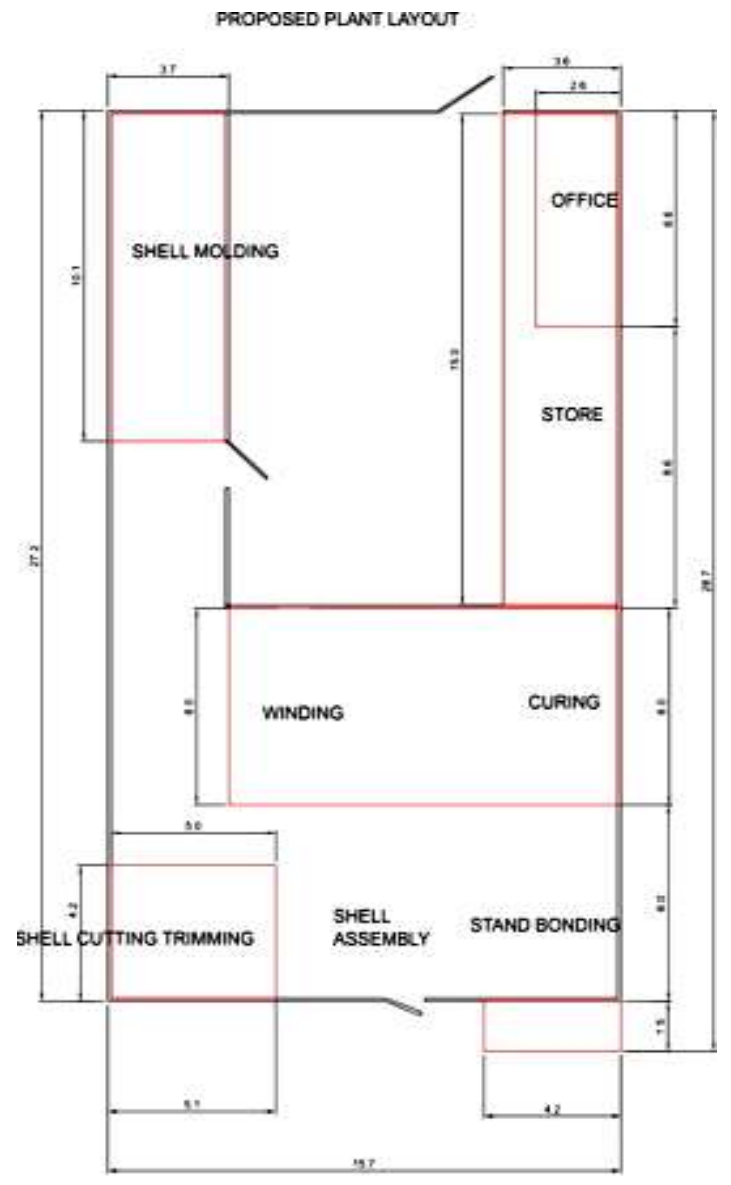

Fig -3: Proposed Plant Layout

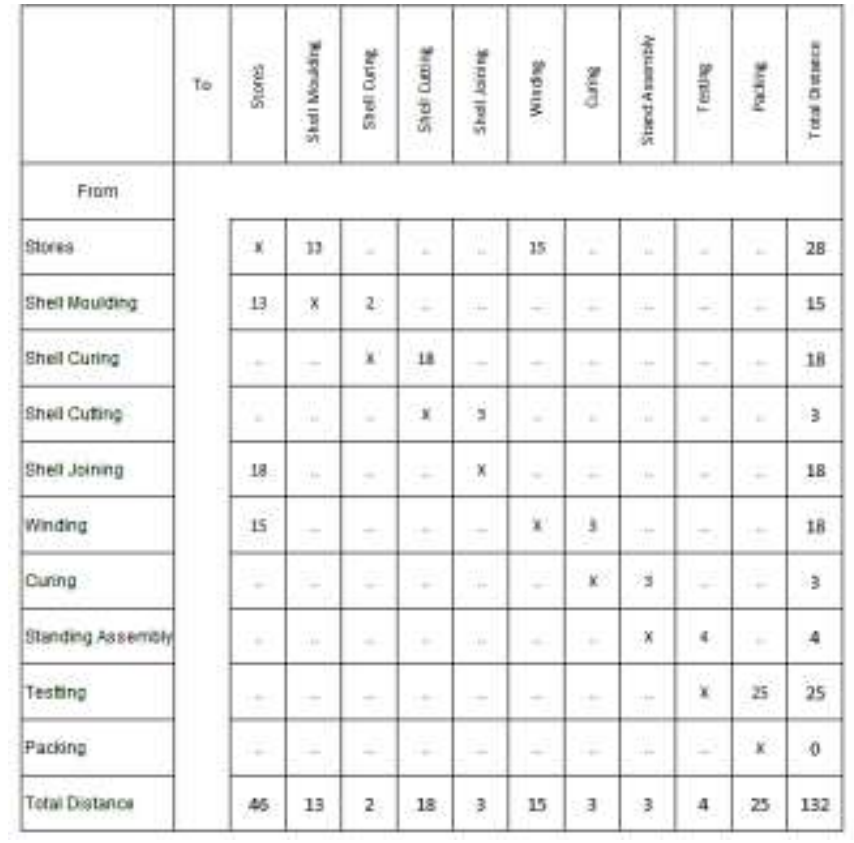

Chart -5: Travel Chart-Proposed Layout

\section{DATA ANALYSIS}

Present plant layout and team of 12 labour working for nine hours shift produces five numbers of TM860-32 swimming pool filter, so cycle time per TM860-32 model per labour is calculated to be 21.6 hours. Using process flow chart for shell moulding and winding, identifying losses and simple changes like proper arrangement so to get quick access, improved communication with stores in regards to work orders, training production operators for quality check, use of hand trolley for material movement will reduce travel distance by $36.4 \mathrm{~m}$ and time by $42 \mathrm{mins}$. Doing multi bonding as per multi activity chart will reduce bonding cycle time by7.72mins and layout modification will reduce travel distance by $49 \mathrm{~m}$. The travel distance of $85.4 \mathrm{~m}$ saved converted into time gives saving of 14.23 mins. So,the total time saved by proposed layout and modification will be $63.95 \mathrm{mins}$. The saving of $63.95 \mathrm{mins}$ results in labour productivity improvement by 0.5 job per day.

\section{PRODUCTIVITY ANALYSIS}

The operator has to search shell die for shell moulding as shell dies are not arranged in systematic manner according to pool filter model. Proper arrangement in line with $5 \mathrm{~S}$ practice will result in reducing delay time and proper arrangement can be accomplished within a day by two workers. There is no communication of sales and production with store, which results in waiting and travel of operator to store, the same can be eliminated if one soft or hard copy of work order is issued to stores. The use of hand trolleys will also result in considerable travel time and also reduce operator fatigue. Modification of layout also saves travel distance; these modifications will take one day for team of four. The cost incurred on doing changes will be Rs.17, 920. All modification will result in increase production rate and production of TM860-32 will raise from 125 Nos. to 137 Nos. thus reducing labour cost per job from Rs.1008 to 
Rs.920. TM 860-32 profit is Rs.2950 per job, productivity increase by $12 \mathrm{jobs}$ per month will give increase in profit by Rs.35,400 which is equivalent $4.7 \%$ increase in profit for first year after take away modification cost and then after $9.6 \%$ for next years.

\section{CONCLUSION AND FUTURE SCOPE}

Beak even analysis concludes that this process can be improved using simple work study charts and diagrams. The implementation of proposed modification will eliminate idle time of worker and thus reducing work cycle time for producing swimming pool filters. From the comparison between present method and propose method, it is found that proposed method are best alternative towards increasing labour productivity. After implementing of proposed method on swimming pool filter production it will increase production by 12 numbers per month as compare to present method. This proposed improvement will reduce worker idle time and increase labour productivity by $9.6 \%$, and also increase profit of company.

After proposed modification it can be further extended to carry out work study using work pro or arena software to validate results, and compare results of manual work study. Other tools like two handed process chart can also be used to stand moulding operations to eliminate unnecessary hand movements. Work study can exended to all operations and all products along with micromtion study.

\section{ACKNOWLEDGEMENT}

I give special thank to composite fiber company management, staff and operators who gave their cooperation to carry out these study.

\section{REFERENCES}

[1]. Gruberg T. A review of improvements methods in manufacturing operations. Work study. 2003 April 1; 52(2): 89-93

[2]. Kanawaty G. Introduction to work study. International Labour Organization; 1992

[3]. ILO.,1986. Introduction to Work Study, International Labour Office (ILO) Publication, Geneva.

[4]. Duran C, Cetinedere A, Aksu YE. Productivity improvement by work and time study technique for earth energy-glass manufacturing company. Procedia Economics and Finance. 2015 Dec 31; 26:109-13

[5]. Al-Saleh KS. Productivity improvement of a motor vehicle inspection station using motion and time study techniques. Journal of King Saud University-Engineering Science 2011 Jan 31; 23(1): 23-41

[6]. Singh MD, Shah Saurabh K, Patel Sachin B, Patel Rahul B, Pansuria Ankit P. To improve Productivity by using work wtudy \& design a fixture in small scale industry. International Journal on Theoretica and Applied Research In Mechanical Engineering. 2012; 1(2):75-81

\section{BIOGRAPHIES}

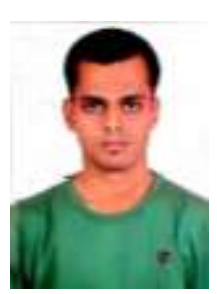

Amol N. Patil is Assistant Professor in Department of Mechanical Engineering at Agnel Institute of Technology and Design, Assagao, Bardez Goa, India. He did his Masters from BVBCET-Hubli in Production Management. His areas of interest are Six Sigma, Quality Management, Lean Management, Supply

Chain Mangement.

Email: a17_patil@yahoo.com

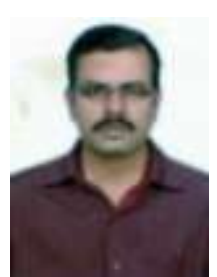

M. Prabakaran is Assistant Professor in Department of Mechanical Engineering at Agnel Institute of Technology and Design, Assagao, Bardez Goa, India. He did his Masters from M. A. M. College of Engineering, Trichy, Tamilnadu. His areas of interest are Six Sigma, Manufacturing, Uncoventional Machining process, Optimization and modeling. Email:global.prabhakaran@gmail.com 